\title{
MARCADOR ISOENZIMÁTICO DE DORMÊNCIA EM SEMENTES DE ARROZ1
}

\author{
ANTONIO RODRIGUES VIEIRA ${ }^{2}$, JOÃO ALMIR OLIVEIRA ${ }^{3}$, RENATO MENDES GUIMARÃES ${ }^{4}$, ÉDILA \\ VILELA DE RESENDE VON PINHO ${ }^{4}$, CARLOS EDUARDO PEREIRA ${ }^{5}$, \\ ALINE DA CONSOLAÇÃO SAMPAIO CLEMENTE ${ }^{6}$
}

\begin{abstract}
RESUMO - Objetivando avaliar as alterações que ocorrem durante o período de dormência das sementes de arroz irrigado, conduziram-se três experimentos sob diferentes condições de armazenamento. Sementes da cultivar Rio Grande, com alta intensidade de dormência pós-colheita, foram acondicionadas em sacos de papel multifoliado e armazenadas por um período de 12 meses, em câmara fria e seca $\left(10^{\circ} \mathrm{C}\right.$ e $50 \%$ de umidade relativa) em armazém convencional em três localidades. Trimestralmente foram feitas avaliações por meio do teor de água, teste de germinação, alterações nos perfis eletroforéticos das isoenzimas Polifenoloxidase (PPO), Peroxidase (PO), Alfa-amilase ( $\alpha$-AM) e Beta-amilase ( $\beta$-AM) em gel de acrilamida e, de grupos redutores pela espectrofotometria. $\mathrm{O}$ tempo e as condições de armazenamento influenciam na superação da dormência das sementes, sendo que, em ambiente de armazém convencional, sementes de arroz superam a dormência em períodos de tempos menores que as sementes armazenadas em câmara fria e seca. As mudanças na atividade das enzimas $\alpha$-AM e P.P.O. possuem relação direta com as alterações na porcentagem de germinação, pois, enquanto a atividade da $\alpha$-AM aumenta a da P.P.O. diminui à medida que a dormência é superada, sugerindo ser a atividade dessas enzimas um promissor indicador da intensidade de dormência das sementes de arroz. Entretanto, a atividade das enzimas P.O. e $\beta$-AM não se correlacionam com a dormência em sementes de arroz.
\end{abstract}

Termos para indexação: Oryza sativa, fisiologia, armazenamento.

\section{ISOENZYMATIC MARKER FOR SEED DORMANCY IN RICE}

\begin{abstract}
Aiming to evaluate the alterations that occur during the dormancy period of irrigated rice seeds, three experiments were carried out at different storage conditions. Seeds from Rio Grande cultivar, highly post-harvest dormant seeds, after preparation, were placed in multilayered paper bags and stored for 12 months, in a cold and dry $\left(10^{\circ} \mathrm{C}\right.$ and $50 \%$ of relative humidity $)$ and in three conventional storage. Every three months, water content, germination, alterations in the electrophoretical profile of the isoenzymes Polyphenoloxidase (PPO), Peroxidase (PO), Alpha-amylase ( $\alpha$-AM), Beta-amylase ( $\beta$-amylase) in polyacrilamide gel and reducing groups by spectrophotometer were evaluated. Storage conditions and duration have influenced the dormancy breakage, and, in the conventional storage environment, rice seeds have broken dormancy faster than the ones stored in cold and dry chamber. Changes in $\alpha-\mathrm{AM}$ and PPO activities are related to alterations in the germination percentage, that is,
\end{abstract}

\footnotetext{
${ }^{1}$ Submetido em 07/04/2007. Aceito para publicação em 13/11/2007. Trabalho financiado pela FAPEMIG.

${ }^{2}$ Eng ${ }^{\circ}$ Agro ${ }^{\circ}$, Dr., Pesquisador, EPAMIG/CTSM, Cx. Postal 176, 37200000, Lavras-MG. e-mail: arvieira@ufla.br

${ }^{3}$ Biólogo, Dr., Professor, UFLA, Cx. Postal 37, 37200-000, Lavras-MG. e-mail: jalmir@ufla.br
}

${ }^{4}$ Engo ${ }^{\text {Agro }}{ }^{\text {, }}$ Dr., Professor, UFLA, Cx. Postal 37, 37200-000, Lavras-MG. e-mail: renatomg@ufla.br

${ }^{5}$ Doutorando, UFLA, Cx. Postal 37, 37200-000, Lavras-MG. e-mail: ce-pereira@bol.com.br

${ }^{6}$ Mestranda, UFLA, Cx. Postal 37, 37200-000, Lavras-MG. e-mail: alineagrolavras@gmail.com 
while the $\alpha$-AM activity increases, PPO activity decreases as dormancy is broken, suggesting these enzymes activities as a promising indicator of dormancy intensity. However, PO and $\beta$-AM activities are not related to dormancy in rice seeds.

Index terms: Oryza sativa, physiology, storage.

\section{INTRODUÇÃO}

Com o desenvolvimento da agricultura, associado à crescente demanda por avanços tecnológicos, o aspecto qualidade cresce em importância, não só pela elevação do grau tecnológico, como também pela maior competitividade entre as instituições produtoras de sementes. No controle de qualidade interno dessas empresas, a avaliação da qualidade das sementes, é de extrema importância para qualquer decisão a ser tomada com relação ao destino das mesmas.

Em se tratando de sementes de cultivares irrigadas de arroz, o fator dormência presente nessas é limitante para o conhecimento da sua qualidade fisiológica, principalmente no período em que essas permanecem armazenadas. Nesse sentido, o monitoramento dessa dormência, sem dúvida é um ponto importante a ser considerado quando se quer encontrar indicadores que possam determinar a velocidade com que é superada.

Dopontode vistafisiológico, algunsaspectos relacionados com o mecanismo de dormência em sementes de arroz tem sido elucidados, havendo ainda, no entanto, aspectos a serem estudados. Segundo Delouche \& Nguyen (1964), a dormência em arroz seria devido à presença de inibidores da germinação localizados no pericarpo, os quais são capazes de fixar o $\mathrm{O}_{2}$, reduzindo desta forma sua disponibilidade para o embrião. Da mesma forma, Bewley \& Black (1982) relatam, que vários compostos fenólicos podem atuar como inibidores da elongação celular ou consumir oxigênio durante o processo de oxidação, restringindo deste modo, a quantidade de oxigênio que chega ao embrião. Neste sentido, Vieira (1991) e Bewley \& Black (1994) encontraram que a oxidação de compostos fenólicos, assim como a alta atividade respiratória em tecidos da cobertura (glumelas e pericarpo), tais como em sementes de arroz, limitariam a disponibilidade de oxigênio para o embrião, conseqüentemente, retardando a germinação das sementes.

De maneira semelhante, pouco se sabe a respeito da atividade enzimática nos processos metabólicos dessas sementes. Recentemente, técnicas empregadas na detecção desta atividade, no período anterior e posterior à germinação, têm sido utilizadas para determinar as alterações bioquímicas que ocorrem nas sementes. Neste sentido, a produção e quantidade de certos metabólitos podem oferecer uma indicação mais realista da condição de dormência das sementes. Entretanto, Bragantini (1985) relata que embora já existam diversas técnicas baseadas na atividade enzimática como método de avaliação da viabilidade das sementes, somente algumas das muitas enzimas envolvidas no processo têm sido investigadas.

De acordo com Braverman (1967), Teisson (1979), Nickerson \& Rosinvallii (1980), a oxidação enzimática dos fenóis ocorre por meio de grupos de isoenzimas: as polifenoloxidases e as peroxidases. A oxidação dos compostos fenólicos por enzimas como a polifenoloxidase tem sido objetivo de várias pesquisas, uma vez que esta enzima catalisa reações que podem ocasionar uma redução na atividade enzimática (Whitaker, 1972). Já as peroxidases catalisam as reações de uma grande variedade de compostos em plantas superiores, (Barz \& Hoesel, 1979). Entre esses compostos estão os fenóis, cuja oxidação pelas peroxidases é bastante conhecida. No entanto, o efeito das peroxidases na germinação de sementes é devido, tanto à sua ação benéfica oxidativa dos compostos fenólicos, possíveis inibidores naturais da germinação, quanto ao seu efeito competidor pelo oxigênio disponível a esta, neste caso, retardando-a ou inibindo-a.

De acordo com Nedel et al. (1996), dentro de um grupo de enzimas, a $\alpha$ e a $\beta$-amilases estão envolvidas no principal sistema de degradação do amido. O desenvolvimento da atividade da amilase constitui um importante evento, podendo ser detectado durante o início da germinação das sementes, sendo seu principal papel, disponibilizar substratos para utilização da plântula até que ela se torne fotossinteticamente auto-suficiente.

Um grande número de tipos de dormência de sementes decorre do bloqueio da ação da $\alpha$-amilase. A ocorrência desta enzima é largamente distribuída nas plantas, principalmente associada com a $\beta$-amilase. A $\alpha$-amilase presente nas sementes dormentes encontra-se em pequenas quantidades, mas durante a germinação todas as sementes rapidamente desenvolvem esta enzima. Desta maneira a $\alpha$-amilase pode ser prontamente encontrada nas sementes em germinação (Mayer, 1976). Nesse sentido, Vieira et al. (2002), estudando a eficiência da aplicação de $\mathrm{GA}_{3}$, em quatro concentrações 
e três tempos de embebição, para superar a dormência em sementes de arroz, constatou que o aumento da concentração de giberelina e tempo de embebição das sementes propiciaram um correspondente aumento na atividade da $\alpha$-amilase. Já em trabalhos realizados com trigo, Nandi et al. (1995), relatam que a $\beta$-amilase é de longa vida e não é sintetizada durante o início da germinação. Entretanto, usando essencialmente a mesma técnica, Okamoto \& Akazawa (1980), demonstraram nova síntese de $\beta$-amilase durante o início da germinação de sementes de arroz.

De uma maneira geral, há muitos estudos relacionados com a quebra de reserva de amido em sementes de arroz, mas as propriedades das enzimas degradadoras de amido incluindo a $\alpha$ e $\beta$-amilase não estão bem caracterizadas.

Apesar de existirem ainda necessidades de muitos estudos nessa área, algumas técnicas têm se mostradas promissoras para avaliação da qualidade das sementes. Entre elas estão a eletroforese e a espectrofotometria. Estas técnicas possuem as vantagens de serem confiáveis, requererem pequenas quantidades de amostras e permitir análise simultânea de diversos lotes, além de conferirem rápida separação com alta resolução. Certamente, os resultados alcançados com a utilização dessas técnicas poderão contribuir para o entendimento das alterações bioquímicas que ocorrem nas sementes dormentes de cultivares irrigadas de arroz, trazendo informações essenciais de reflexo positivo na pesquisa e produção dessas sementes.

Diante disso o objetivo dessa pesquisa foi correlacionar as alterações durante o estádio de dormências das sementes de arroz, armazenadas sob diferentes condições de temperatura e umidade relativa, com testes fisiológicos, perfis eletroforéticos de atividades isoenzimáticas e espectrofotometria, buscando assim, um maior entendimento da dinâmica de superação da dormência, necessário para aprimoramento da eficácia das técnicas de manejo e avaliação da qualidade dessas sementes.

\section{MATERIAL E MÉTODOS}

Foram utilizadas sementes de arroz, da cultivar irrigada Rio Grande, produzidas pela empresa EPAMIG, em Lambari - MG -Brasil.

Para detectar a intensidade de dormência inicial do lote, após a secagem natural até $9,5 \%$ de umidade e beneficiamento as sementes foram submetidas ao teste de germinação conforme prescrições contidas nas Regras para Análise de Sementes (Brasil, 1992), antes e após o tratamento para superação de sua dormência em estufa de circulação forçada de ar a $40^{\circ} \mathrm{C}$ por sete dias (Vieira, 1991).
Detectada a dormência das sementes (Tabela 1), um lote de $240 \mathrm{~kg}$ foi expurgado com fosfina, homogeneizado, dividido em 12 partes de $20 \mathrm{~kg}$ cada, acondicionado em sacos de papel multifoliado e armazenados na UFLA em Lavras MG e na EPAMIG em Patos de Minas - MG, por um período de 12 meses. Na UFLA foram utilizados dois ambientes de armazenamento, um aberto sem controle de temperatura e umidade relativa (armazém convencional) e outro com controle (câmara fria e seca), enquanto na EPAMIG foi utilizado apenas o armazém convencional. As sementes submetidas ao ambiente de armazém convencional tiveram a temperatura e a umidade relativa do ar monitorado por meio de termohigrógrafo. Em Lavras os valores médios mensais de temperaturas mínimas obtidas no período variaram entre 15 e $20^{\circ} \mathrm{C}$ e de máximas entre 22 e $28^{\circ} \mathrm{C}$ enquanto para os da umidade relativa a variação foi entre 60 e $72 \%$. Já para Patos de Minas os valores foram entre 13 e $20^{\circ} \mathrm{C}$ e, 23 e $33^{\circ} \mathrm{C}$ para temperaturas e entre 53 e $82 \%$ para umidade relativa. Nas condições de câmara fria e seca, o ambiente foi ajustado para manter a temperatura próxima a $10^{\circ} \mathrm{C}$ e a umidade relativa do ar de $50 \%$.

Foram coletadas amostras trimestralmente em cada um dos ambientes de armazenamento e realizados os seguintes testes:

Teor de água - efetuado, pelo método de estufa $105 \pm$ $3^{\circ} \mathrm{C}$ durante 24 horas, utilizando duas repetições para cada amostra, conforme prescrições das Regras para Análise de Sementes (Brasil, 1992). Os resultados foram expressos em porcentagem média por amostra (base úmida).

Teste de germinação - realizado utilizando-se quatro repetições de 50 sementes por amostra, as quais foram distribuídas em papel toalha no sistema de rolo, umedecido com água em quantidade equivalente a 2,5 vezes o peso do papel, sendo dispostos em germinador previamente regulado

TABELA. 1. Médias de porcentagem de germinação (GER) e de sementes dormentes (SD) de arroz após a secagem e beneficiamento das sementes, com e sem tratamento para superar a dormência.

\begin{tabular}{ccccc}
\hline \multirow{2}{*}{ Cultivar } & \multicolumn{3}{c}{ Após beneficiamento } \\
\cline { 2 - 5 } & \multicolumn{2}{c}{ Sem tratamento } & Com tratamento \\
\hline \multirow{2}{*}{ Rio Grande } & GER & SD & GER & SD \\
& 45 & 51 & 91 & 3 \\
\hline
\end{tabular}


a $30^{\circ} \mathrm{C}$. As avaliações foram feitas aos sete e 14 dias após a semeadura, seguindo as prescrições contidas nas Regras para Análise de Sementes (Brasil, 1992), computando-se apenas as porcentagens de plântulas normais.

No final do teste, as sementes que permaneceram dormentes tiveram sua viabilidade avaliada pelo teste de tetrazólio, para comprovação de sua dormência. Para tanto, seccionou-se as sementes longitudinalmente, através do embrião e uma das metades foi submersa em solução de 2,3,5-trifenil cloreto de tetrazólio a $0,1 \%$, por quatro horas e na ausência de luz a $30^{\circ} \mathrm{C}$, para coloração. Após esse período, as sementes foram lavadas em água corrente e tiveram sua viabilidade avaliada, seguindo os critérios estabelecidos pelas Regras para Análise de Sementes (Brasil, 1992), sendo os resultados expressos em porcentagem de sementes dormentes para cada ambiente.

Atividade de enzimas - Determinada por eletroforese e espectrofotometria para as isoenzimas polifenoloxidase (PPO-EC 1.14.18.1), peroxidase (PO-EC 1.11.1.7), $\alpha$-amilase $(\alpha$-AM-EC 3.2.1.1) e $\beta$-amilase ( $\beta$-AM-EC 3.2.1.2).

Amostras de 100 sementes de cada ambiente foram homogeneizadas e colocadas para germinar no sistema de rolo de papel em germinador à $30^{\circ} \mathrm{C}$, até que $50 \%$ ou mais de uma das amostras iniciasse protrusão da radícula (aproximadamente em 60 horas). Os cariópses, contendo ou não a radícula em início de protrusão, foram triturados a frio, em moinho refrigerado $\left(4^{\circ} \mathrm{C}\right)$ e armazenados em congelador, a $-84^{\circ} \mathrm{C}$.

Eletroforese-para determinara atividade enzimática pormeio dessa técnica foram utilizadas $100 \mathrm{mg}$ de sementes trituradas de cada ambiente, às quais foram adicionados $200 \mu \mathrm{L}$ do tampão de extração (Tris-HCl 0,2M; $1 \% \beta$ mercapto-etanol; 0,4 \% PVP; 0,4\% PEG + 1mM EDTA; pH 8,0). Os tubos eppendorf, contendo os homogeneizados, foram mantidos em gelo por 24 horas. Após esse período, as amostras foram ressuspendidas e centrifugadas a $16.000 \mathrm{x} / \mathrm{g}$ por 60 minutos a $4^{\circ} \mathrm{C}$, e os sobrenadantes recolhidos. De cada sobrenadante obtido foram aplicados $40 \mu \mathrm{L}$ em géis de poliacrilamida a $4,5 \%$ (gel concentrador) e 7,5\% (gel separador contendo $5 \%$ de amido solúvel no caso das amilases). O sistema gel/eletrodo utilizado foi Tris-glicina $\mathrm{pH}$ 8,9. As corridas eletroforéticas foram efetuadas a $12 \mathrm{~mA}$ no gel concentrador e $24 \mathrm{~mA}$ no gel separador. Após a eletroforese, os géis sob condições de ambiente foram revelados e corados para as isoenzimas peroxidase, $\alpha$ e $\beta$-amilases de acordo (Alfenas et al., 1998).
Espectrofotometria - Em parte dos sobrenadantes obtidos após extração, foram determinados grupos redutores conforme Noelting \& Bernfeld (1948). Para tanto, foi adicionado amido na concentração de $0,5 \%$ aos sobrenadantes e em cada determinação, a mistura de reação foi incubada por cinco diferentes períodos de tempo. Controles sem enzima (branco de substrato) e sem substrato (branco de enzima) foram incubados do mesmo modo que os tubos experimentais. A atividade da isoenzima calculada foi expressa em m moles de substrato hidrolisado por minuto (mileunidade $-\mathrm{mU}$ ).

Para a isoenzima polifenoloxidase o método de extração foi o mesmo descrito por Draetta \& Lima (1976), onde foram pesados $5 \mathrm{~g}$ de cada amostra previamente moída e adicionados $40 \mathrm{~mL}$ da solução de fosfato de potássio $0,1 \mathrm{~mol} . \mathrm{L}^{-1}$ a $\mathrm{pH}$ 6,0, agitando-se a amostra por 5 minutos sob refrigeração. Após a agitação, foi feita a filtragem em papel filtro Whatman $\mathrm{n}^{\circ}$ 1. A atividade da polifenoloxidase foi determinada pelo método descrito por Ponting \& Joslyng (1948), utilizando-se o extrato da amostra sem DOPA (3,4-dihidroxifenil-alanina) como branco, sendo os resultados expressos em unidades por minuto por gramas (U.min $\left.{ }^{-1} \cdot \mathrm{g}^{-1}\right)$.

Procedimento estatístico - foi utilizado o delineamento inteiramente casualizado com quatro repetições, sendo os tratamentos em esquema de parcela sub-dividida, onde os tratamentos da parcela foram constituídos por três ambientes de armazenamento e as sub-parcelas, pelas épocas de avaliação. Para comparação dos resultados, foram utilizadas análises de variância, fazendo-se a transformação dos valores expressos em porcentagem para arc sen $\sqrt{x / 100}$, exceção feita à variável umidade. Para as variáveis que apresentaram efeito significativo pelo teste $\mathrm{F}$, realizou-se análise de regressão.

\section{RESULTADOS E DISCUSSÃO}

Verifica-se na Tabela 1 que as sementes não submetidas ao tratamento para superação da dormência, tiveram como resultado, uma alta porcentagem de sementes dormentes.

Nas Figuras 1, 2 e 3, encontram-se representados os resultados médios ajustados e as equações de regressão referentes à avaliação do teor de água, germinação e sementes dormentes de arroz, armazenadas nos diferentes locais, sob condições de armazém convencional e câmara fria e seca.

Pela Figura 1 pode ser observado que houve uma tendência de aumento do teor de água inicial das sementes (9,5\%) até o sexto mês de armazenamento (próximo de $12 \%$ para as condições de câmara fria e seca; $11,5 \%$ para armazém 

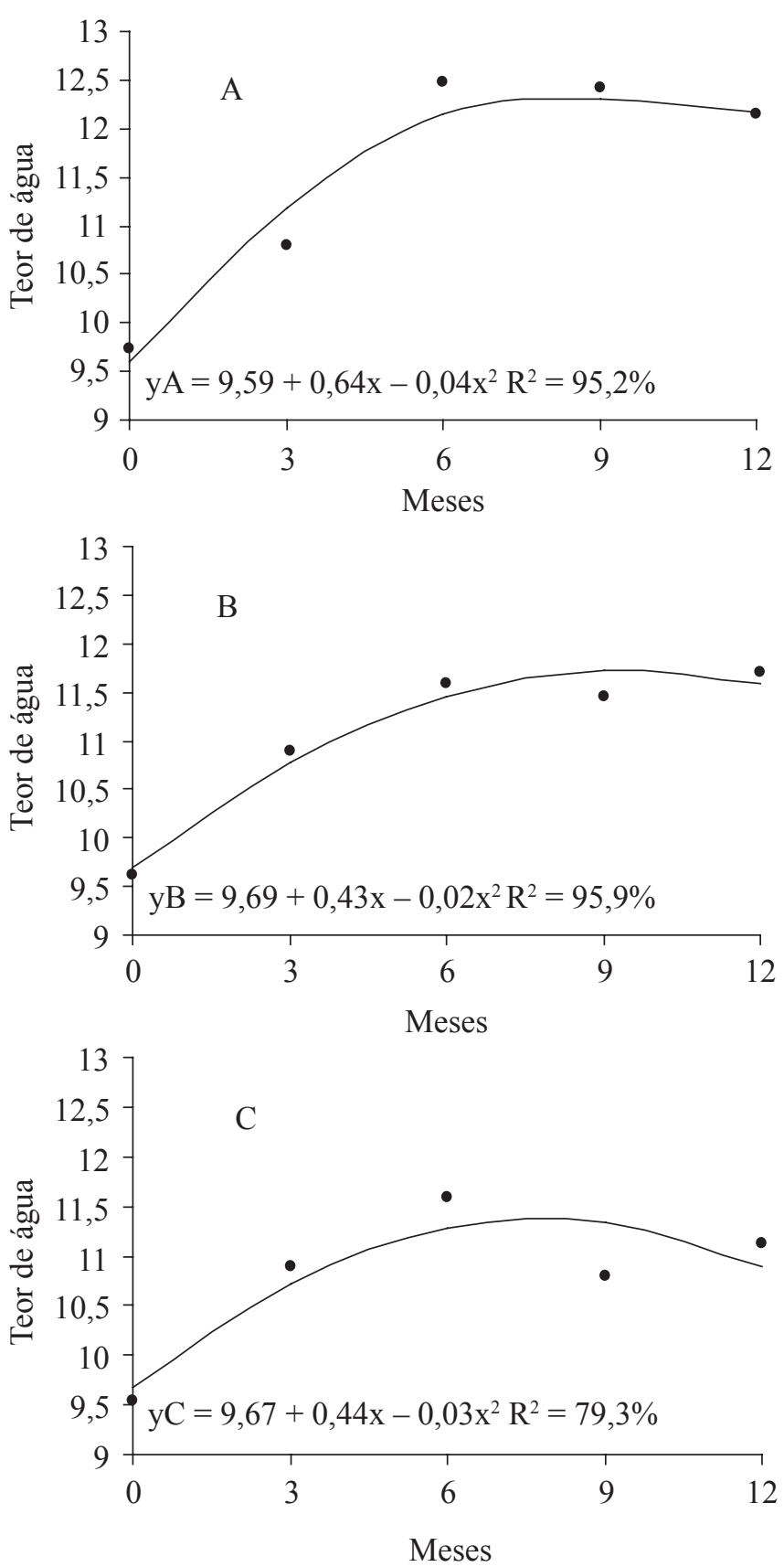

FIGURA 1. Porcentagem de água de sementes de arroz, armazenadas em ambiente aberto (armazém convencional) e em ambiente controlado (câmara fria e seca), em Lavras e Patos de Minas, durante 12 meses.

convencional em Lavras e 11\% para armazém convencional em Patos de Minas). Entretanto a partir desse mês, os teores de água das sementes armazenadas permaneceram nesses patamares até o $12^{\circ}$ mês de armazenamento. Foi verificado
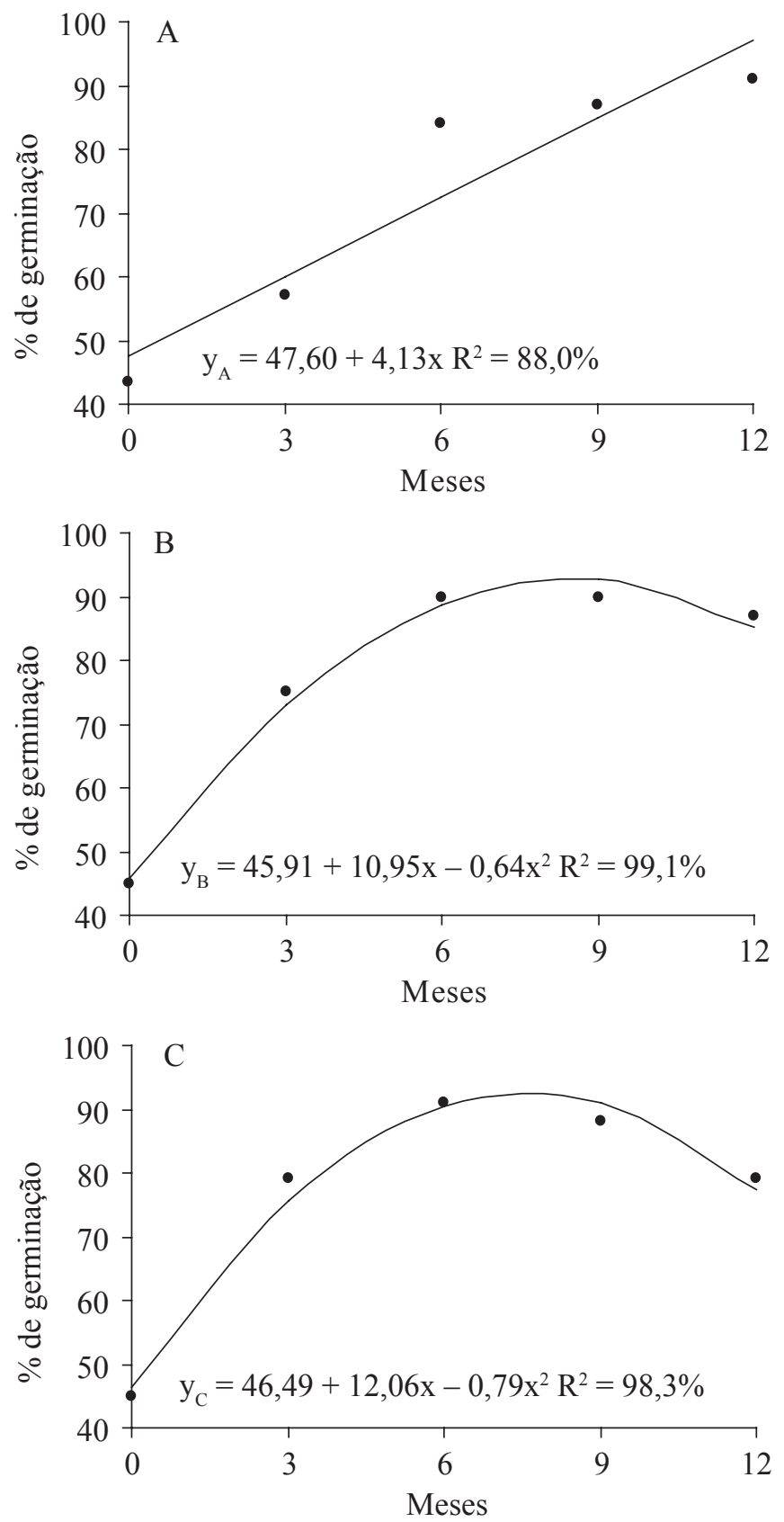

FIGURA 2. Porcentagem de germinação de sementes de arroz, armazenadas em ambiente aberto (armazém convencional) e em ambiente controlado (câmara fria seca), em Lavras e Patos de Minas, durante 12 meses.

nesse período que as umidades relativas médias obtidas nos armazéns convencionais tenderam a manter-se constante, embora tenha ocorrido uma variação muito pequena durante o período chuvoso. Tais observações são reforçadas por 

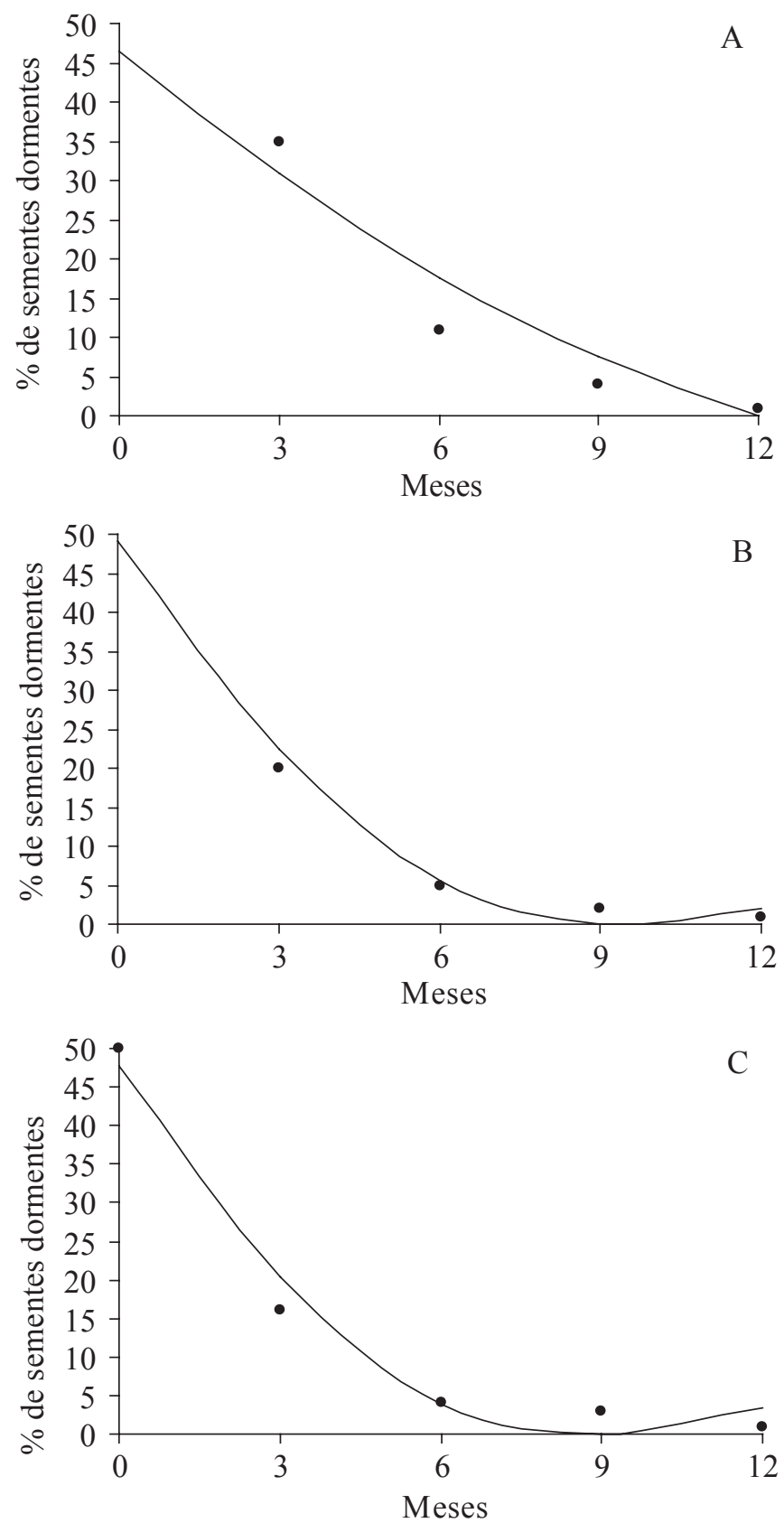

FIGURA 3. Porcentagem de sementes dormentes de arroz, armazenadas em ambiente aberto (armazém convencional) e em ambiente controlado (câmara fria e seca), em Lavras e Patos de Minas, durante 12 meses.

relatos de Greg et al. (1970), os quais mencionaram que as sementes, devido à sua propriedade higroscópica, têm o seu conteúdo de água variando com a umidade relativa do ar.

Pode se observar, pela Figura 2, que, quando armazenadas sob condições de armazém convencional a germinação das sementes ocorreu de maneira mais rápida que na câmara fria e seca, ao longo do período de armazenamento, tanto em Lavras quanto em Patos de Minas. Isto indica que, temperaturas mais elevadas do ambiente de armazenamento reduzem a dormência das sementes, com conseqüente aumento na porcentagem de germinação. Tais resultados assemelham-se aos relatos de Bewley \& Black (1994), de que a dormência das sementes diminui com o decorrer do período de armazenamento, principalmente com a elevação da temperatura.

Em câmara fria e seca, a maior germinação ocorreu no $12^{\circ}$ mês de armazenamento, enquanto nas duas condições de armazém convencional foi a partir do $6^{\circ}$ mês. Esse resultados confirmam a hipotese de que existe uma ação de fatores intrínsecos à semente durante o armazenamento, principalmente inibidores da germinação, tais como os compostos fenólicos presentes no endosperma, embrião e casca, os quais promovem a redução na disponibilidade do oxigênio para o embrião (Hayashi, 1987 e Amaral, 1992). Acredita-se que, quando se utiliza o armazenamento da semente seca por um determinado período, existe a possibilidade de ocorrer a difusão lenta e paulatina de $\mathrm{O}_{2}$ para o seu interior, determinando a redução gradativa da quantidade de inibidores da germinação, favorecendo a superação da dormência e, conseqüentemente, a sua germinação (Olatoye \& Hall, 1972). Vale ressaltar que, sementes dormentes de arroz armazenadas em câmara fria e seca, preservam uma pequena taxa de dormência até próximo aos seis meses de armazenamento, época apropriada para a semeadura. Entretanto ainda pode ser observado nessa figura que, a partir do $9^{\mathrm{a}}$ mês houve uma tendência de redução da porcentagem de germinação nas condições de armazém convencional, devido à deterioração natural das sementes. Provavelmente, tal fato esteja relacionado às variações de umidades relativas do ar durante o armazenamento, concordando com Barton (1961), a qual relatou que as sementes armazenadas sob condições de flutuação de umidade relativa do ar, podem perder a viabilidade mais rapidamente do que as sementes armazenadas em condições de umidade constante.

Comparando a Figura 3, onde se encontram as representações da porcentagem de sementes dormentes, com a anterior (Figura 2), observa-se uma relação inversa, o que já era esperado, pois, onde a porcentagem de sementes dormentes foi menor, a germinação foi maior.

Na Figura 4 visualiza-se a avaliação da a atividade $\alpha$-amilase nos tratamentos referenciais (sementes no início do armazenamento sem e com tratamento para a superação da dormência) e ao longo do período de armazenamento, sob condição de câmara fria e seca e em armazém convencional. 
A $\alpha$-amilase apresenta baixa atividade nas sementes no início do armazenamento quando não se aplicou tratamento para superar a dormência e nas sementes onde foi feito esse tratamento a atividade é alta. Isso indica que a atividade dessa enzima está diretamente relacionada com a dormência das sementes. Tal fato pode ser comprovado pelos dados da Tabela 1, onde se encontram os resultados de porcentagem de germinação e de sementes dormentes, referentes às mesmas amostras. Essas observações reforçam relatos de Petruzzelli \& Taranto (1990) e Livesley \& Bray (1991), os quais enfatizam que, em sementes com alto índice de dormência, a atividade da amilase tem sido pequena. Pode ser observado também que, com o aumento do período de armazenamento houve um acréscimo na atividade da $\alpha$-amilase para as sementes armazenadas em armazém convencional em ambas localidades estudadas, sendo que, a atividade enzimática atingiu os níveis mais elevados a partir do sexto mês de armazenamento permanecendo até o final do ensaio, o que coincide com os resultados de porcentual de germinação e de sementes dormentes (Figuras 2 e 3). Da mesma forma, as sementes armazenadas em ambiente de câmara fria e seca a atividade da $\alpha$-amilase foi aumentando de maneira gradativa ao longo do armazenamento, atingindo os maiores níveis aos 12 meses quando a dormência estava superada, coincidindo também com os resultados obtidos para porcentagem de germinação e de sementes dormentes contidos nas Figuras 2 e 3. De modo geral, esses resultados estão coerentes com aqueles encontrados por Shaw \& Ou-Lee citados por Das \& Sen-Mandi (1992), os quais trabalhando com sementes de arroz, relatam ser a atividade da $\alpha$-amilase essencial para a germinação das sementes.

Resultados similares foram obtidos pela espectrofotometria na quantificação da atividade enzimática dessa enzima (Tabela 2). Embora as sementes armazenadas em armazém convencional tenham apresentado maiores valores de atividade pela espectrofotometria, nos meses finais de armazenamento, esta superioridade não foi constatada da mesma forma pela atividade da $\alpha$-amilase no gel de eletroforese. Provavelmente, a partir de um certo nível de atividade, não ocorre aumento correspondente na degradação do amido. Tais resultados coincidem com aqueles encontrados por Vieira et al. (2002), quando da realização de suas pesquisas com sementes de arroz cultivar Urucuia.

A dormência vai sendo superada, a atividade da enzima polifenoloxidase tende a decrescer. Segundo Zawistowski et al. (1991), a polifenoloxidase está presente na membrana plasmática das sementes e com a desestruturação dessas membranas a enzima entra em contato com os compostos fenólicos catalisando a sua oxidação e reduzindo o seu conteúdo nas sementes. Nesse contexto, como os compostos fenólicos são inibidores da germinação, pode-se inferir que quanto mais intensa a dormência das sementes maior deverá ser a atividade da polifenoloxidase.

De uma maneira geral, os padrões eletroforéticos da enzima $\alpha$-amilase e a atividade das enzimas $\alpha$-amilase e polifenoloxidase, podem se constituir em importantes técnicas a serem empregadas como marcadores da intensidade de dormência das sementes de arroz. Entretanto, com relação

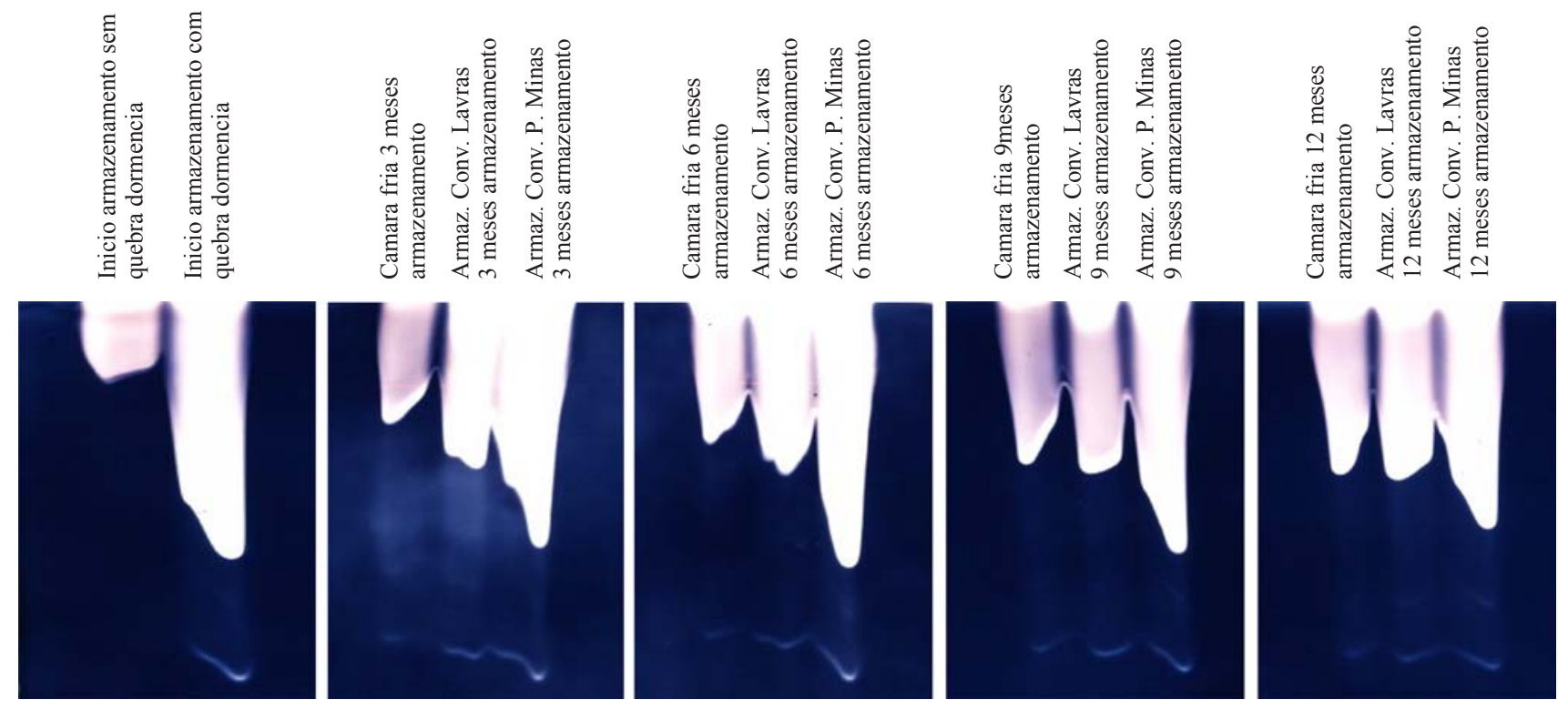

FIGURA 4. Perfis eletroforéticos de atividade enzimática da $\alpha$-amilase, em sementes de arroz recém-germinadas. 
TABELA 2. Valores de atividade da polifenoloxidase $\left(\mathrm{U} \cdot \mathrm{min}^{-1} \cdot \mathrm{g}^{-1}\right.$ ) em extratos de sementes de arroz, quantificadas durante armazenamento em diferentes locais e ambientes.

\begin{tabular}{cccc}
\hline $\begin{array}{c}\text { Épocas } \\
\text { (meses) }\end{array}$ & $\begin{array}{c}\text { Câmara Fria e } \\
\text { Seca Lavras }\end{array}$ & $\begin{array}{c}\text { Armazém } \\
\text { Convencional } \\
\text { Lavras }\end{array}$ & $\begin{array}{c}\text { Armazém } \\
\text { Convencional } \\
\text { Patos de Minas }\end{array}$ \\
\hline 0 & 13,29 & 13,29 & 13,29 \\
3 & 13,53 & 12,48 & 10,11 \\
6 & 10,15 & 10,03 & 7,70 \\
9 & 5,02 & 8,63 & 5,83 \\
12 & 7,82 & 9,80 & 6,88 \\
\hline
\end{tabular}

TABELA 3. Valores de atividade enzimática da $\alpha$-amilase (mU), em extratos de sementes de arroz, quantificadas durante armazenamento em diferentes locais e ambientes.

\begin{tabular}{cccc}
\hline $\begin{array}{c}\text { Épocas } \\
\text { (meses) }\end{array}$ & $\begin{array}{c}\text { Câmara Fria e } \\
\text { Seca Lavras }\end{array}$ & $\begin{array}{c}\text { Armazém } \\
\text { Convencional } \\
\text { Lavras }\end{array}$ & $\begin{array}{c}\text { Armazém } \\
\text { Convencional } \\
\text { Patos de Minas }\end{array}$ \\
\hline 0 & 76,78 & 76,78 & 76,78 \\
3 & 251,18 & 420,23 & 703,71 \\
6 & 256,76 & 464,95 & 701,2 \\
9 & 293,60 & 490,66 & 877,38 \\
12 & 296,95 & 491,19 & 902,00 \\
\hline
\end{tabular}

às enzimas $\beta$-amilase e peroxidase não se pode dizer o mesmo, pois não foi possível quantificar suas atividades em arroz utilizando a eletroforese, uma vez que não houve resposta quando da aplicação do substrato no gel em ambas avaliações.

\section{CONCLUSÕES}

- O tempo e as condições de armazenamento influenciam na superação da dormência das sementes de arroz;

- Em ambiente de armazém convencional, sementes de arroz superam a dormência em períodos de tempos menores que as sementes armazenadas em câmara fria e seca;

- A atividade das enzimas $\alpha$-amilase aumenta e da polifenoloxidase diminui à medida que a dormência das sementes de arroz é superada, durante o período de armazenamento;
- A atividade das enzimas peroxidase e $\beta$-amilase não se correlaciona com a dormência em sementes de arroz.

\section{REFERÊNCIAS}

ALFENAS, A.C.; DUSI, A.; ZERBINI JÚNIOR, F.M.; ROBINSON, I.P.; MICALES, J.A.; OLIVEIRA, J.R.; DIAS, L.A.S.; SCORTICHINI, M.; BONDE, M.R.; ALONSO, S.K.; JUNGHANS, T.G. \& BRUNE, W. Eletroforese de isoenzimas e proteínas afins: fundamentos e aplicações em plantas e microorganismos. Viçosa: Universidade Federal de Viçosa, 1998. 574p.

AMARAL, A.S. Aspectos de dormência em sementes de arroz. Lavoura Arrozeira, Porto Alegre, v.45, n.405, p.3-6, 1992.

BARTON, L.V. Seed preservation and longevity. London: Leonard Hill Books, 1961. 216p.

BARZ, W.; HOESEL, W. Metabolism and degradation of phenolic compounds. In: SWAIN, T.; HARBONE, J.B.; VAN SUMERE, C.F., eds. Biochemistry of plant phenolics. Bélgica, Plenum Press, 1979, vol. XII, p.339-370.

BEWLEY, J.D.; BLACK, M. Physiology and Biochemistry of Seeds in Relation to Germination. Berlim, SpringerVerlag ed., 1982. v.II, 375p.

BEWLEY, J.D. \& BLACK, M. Seeds: physiology of development and germination. 2.ed. New York: Plenum Press, 1994. 445p.

BRAGANTINI, C. Conservação de Sementes. Brasília: MEC, 1985, Módulo 7, 18p. (Sementes: Curso de especialização por tutoria à distância).

BRASIL. Ministério da Agricultura e da Reforma Agrária. Regras para análise de sementes. Brasília: SNDA/DNDV/ CLAV, 1992. 365p.

BRAVERMAN, J.B.S. Vitaminas. In: Introducción a la bioquímica de los alimentos. Barcelona, Omega, 1967. cap. 14, p.206-239.

DAS, G. \& SEN-MANDI, S. Scutellar amilase activity in naturally aged and accelerated aged wheat seeds. Annals of Botany, London, v.69, n.6, p.497-501, 1992.

DELOUCHE, J.C.; NGUYEN, N.T. Methods for overcoming seed dormancy in rice. Journal paper $n^{0}$ 1219. Miss. Agric. Expt. Sta., p.41-49, 1964.

DRAETTA, I.S. \& LIMA, D.C. Isolamentos e caracterização das polifenoloxidases do café. Coletânia do Instituto de Tecnologia de Alimentos, Campinas, v.7, p.3-28, Jan./Jun. 1976.

GREG, B.R.; LAW, A.G.; VIRDI, S.S. \& BALIS, J.S. Seed 
processing. Nova Delhi: Mississipii State University, 1970. $396 p$.

HAYASHI, M. Relation between endogenous germinations inhibitors and dormancy in rice seeds. Japan Agricultural Research Quartely, Tsukuda, v.21, n.3, p.153-161, 1987.

LIVESLEY, M.A. \& BRAY, C.M. The effect of ageing upon $\alpha$-amylase production and protein synthesis by wheat aleurone layers. Annals of Botany, London, v.68, n.1, p.6973, 1991.

MAYER, A.M. \& POLJAKOFF-MAYBER, A. The germination of seeds. 4. ed. Toronto: Pergamon Press, 1989. 270p. Cap.6: Germination stimulators and inhibitors: their effects and their possible regulatory role, p.174-178. MEYER, L.H. Food chemistry. Connecticut: The Avi Publishing Company, 1976. 385p. Cap.3: Carbohydrates, p.65-113.

NANDI, S.; DAS, G.; SEN-MANDI, S. $\beta$-Amilase activity as an index for gemination potencial in rice. Annals of Botany. Calcutta, 1995. v.75, p.463-467.

NEDEL, J.L.; ASSIS, F.N. \& CARMONA, P.S. A planta de arroz-morfologia e fisiologia. Pelotas: UFPEL, 1996. 56p. (Módulo 1 - Curso de Especialização em Produção de Sementes de Arroz Irrigado).

NIKERSON, J.T.R.; ROSINVALLI, L.J. Enzime reactions. In: _. Elementary food science. Westport, AVI, 1980. cap. 8, p.113-121.

NOELTING, G. \& BERNFELD, P. Sur les enzymes amylolytiques III-La $\beta$ amylase: dosage d'activeté et contrôle de l'absence d' $\alpha$-amylase. Helvetica Chimica Acta, Basel, v.31, n.1, p.286-290, 1948.

OKAMOTO, K.; AKAZAWA, T. Denovo synthesys of $\beta$-amylase. In: Enzymic mechanism of starch breakdown in germinating rice seeds, 9. Plant Physiology. 1980. v.63, p.336-340.

OLATOYE, S.T. \& HALL, M.A. Interaction of ethylene and light on dormant weed seeds. In: HEYDECKER, W. (ed.). Seed ecology. Norwich: Pennsylvania State University, 1972. p.233-249.

PETRUZZELLI, L. \& TARANTO, G. Amylase activity and loss of viability in wheat. Annals of Botany, London, v.66, n.4, p.375-380, 1990.

PONTING, J.D. \& JOSLYNG, M.A. Ascorbic acid oxidation and browning in apple tissue extract. Archives of Biochemistry, New York, v.19, p.47-63, 1948.

TEISSON, C. Le brunissement interne de l'ananas. IHistorique. II- Matériel et méthodes. Fruits. Paris, v.34, n.4, p.245-281, 1979.

VIEIRA, A.R. Efeitos de compostos fenólicos na dormência de sementes de arroz (Oryza sativa L.) e eficiência de tratamentos pré-germinativos. Lavras: Escola Superior de Agricultura de Lavras, 1991. 58p. (Dissertação Mestrado).

VIEIRA, A.R.; OLIVEIRA, J.A.; VIEIRA， M.G.G.C.; FRAGA, A.C.; SANTOS, C.D. Action of gibberellic acid $\left(\mathrm{GA}_{3}\right)$ on dormancy and activity of alfa-amylase in rice seeds. Revista Brasileira de Sementes, Londrina - PR, v.24, n.2, p.43-48, 2002.

WHITAKER, H. R. Principles of enzimology for the food sciences. New York: Marcel Dekker, 1972. p.571-582.

ZAWISTOWSKI, J.; BILIADERIS, C.G.; ESKIN, N.A.M. Polyphenoloxidases. In: ROBINSON, D.S.; ESKIN, N.A.M. Oxidative enzymes in foods. New York: Elsevier Applied Science, 1991. p.217-274. 